\title{
Analysis of the immune-inducible transcriptome from microbial stress resistant, rat-tailed maggots of the drone fly Eristalis tenax Boran Altincicek and Andreas Vilcinskas*
}

\author{
Address: Institute of Phytopathology and Applied Zoology, Interdisciplinary Research Center, Justus-Liebig-University of Giessen, Heinrich-Buff- \\ Ring 26-32, D-35392 Giessen, Germany \\ Email: Boran Altincicek - Boran.Altincicek@agrar.uni-giessen.de; Andreas Vilcinskas* - Andreas.Vilcinskas@agrar.uni-giessen.de \\ * Corresponding author
}

Published: 17 September 2007

BMC Genomics 2007, 8:326 doi:10.1/86/147|-2164-8-326
Received: 30 January 2007

Accepted: 17 September 2007

This article is available from: http://www.biomedcentral.com/I47I-2I64/8/326

(c) 2007 Altincicek and Vilcinskas; licensee BioMed Central Ltd.

This is an Open Access article distributed under the terms of the Creative Commons Attribution License (http://creativecommons.org/licenses/by/2.0), which permits unrestricted use, distribution, and reproduction in any medium, provided the original work is properly cited.

\begin{abstract}
Background: The saprophagous and coprophagous maggots of the drone fly Eristalis tenax (Insecta, Diptera) have evolved the unique ability to survive in aquatic habitats with extreme microbial stress such as drains, sewage pools, and farmyard liquid manure storage pits. Therefore, they represent suitable models for the investigation of trade-offs between the benefits resulting from colonization of habitats lacking predators, parasitoids, or competitors and the investment in immunity against microbial stress. In this study, we screened for genes in $E$. tenax that are induced upon septic injury. Suppression subtractive hybridization was performed to selectively amplify and identify cDNAs that are differentially expressed in response to injected crude bacterial endotoxin (LPS).

Results: Untreated E. tenax maggots exhibit significant antibacterial activity in the hemolymph which strongly increases upon challenge with LPS. In order to identify effector molecules contributing to this microbial defense we constructed a subtractive cDNA library using RNA samples from untreated and LPS injected maggots. Analysis of 288 cDNAs revealed induced expression of 117 cDNAs corresponding to 30 novel gene clusters in E. tenax. Among these immune-inducible transcripts we found homologues of known genes from other Diptera such as Drosophila and Anopheles that mediate pathogen recognition (e.g. peptidoglycan recognition protein) or immune-related signaling (e.g. relish). As predicted, we determined a high diversity of novel putative antimicrobial peptides including one $E$. tenax defensin.
\end{abstract}

Conclusion: We identified 30 novel genes of $E$. tenax that were induced in response to septic injury including novel putative antimicrobial peptides. Further analysis of these immune-related effector molecules from Eristalis may help to elucidate the interdependency of ecological adaptation and molecular evolution of the innate immunity in Diptera.

\section{Background}

Eristalis tenax belongs to the hover flies, family Syrphidae (Diptera), with more than 5,000 described species, which occurred late in evolution and radiated in the Early Tertiary [1]. In contrast to the predominantly flower-feeding habitats of adult syrphids, their maggots are found in a very diverse array of habitats. Those of subfamily Eristalinae are saprophagous, coprophagous and aquatic filterfeeders. Combined analysis of molecular and morphological characters supports both frequent shifts 
between larval feeding habitats within the Eristalinae and the monophyly of this subfamily [2]. The rat-tailed maggots of E. tenax are characterized by their extended anal breathing tube that functions as a snorkel and enables survival in waters with anaerobic conditions. They realize a unique ecological niche by preferably living in stagnant aquatic environments with high organic and microbial contamination. Because of the preference of $E$. tenax larvae for dirty waters with anaerobic conditions, they are reliable and prominent indicators in the biological assessment of water quality for extremely high pollution with organic material [3]. They thus represent a suitable model to investigate the trade-offs between the benefits resulting from colonization of habitats lacking predators, parasitoids, or competitors and the investment in immunity against microbial stress.

The innate immunity of insects relies on immediate processes including cellular phagocytosis, encapsulation, hemolymph coagulation, and phenoloxidase activation leading to melanization. On the other hand sustainable defense is achieved by the massive synthesis of antimicrobial peptides like defensins and cecropins $[4,5]$. Insect immunity has been best analyzed in the fruit fly $D$. melanogaster $[6,7]$, but results of comparative genome-wide analysis of immunity-related genes in D. melanogaster, Anopheles gambiae, and Aedes aegypti reveal that effector molecules from these dipteran species exhibit large variations [8]. For example, four defensin and four cecropin genes exist in Anopheles, making these more numerous than in Drosophila whereas some antimicrobial peptides that were identified in Drosophila are absent in Anopheles and Aedes [8]. The maggots of E. tenax have been recognized to be particularly resistant to microbial stress, because they are able to survive in aquatic habitats that are usually not colonized by other dipteran larvae or animals [3]. Hence we were interested to identify the immunerelated genes of this insect.

To selectively identify immune-induced genes we used the subtractive suppression hybridization (SSH) method which amplifies differentially expressed cDNAs and simultaneously suppresses amplification of common cDNAs. This technique has been proven as a suitable tool for identification of immune-related genes in insects [9$11]$ and other invertebrates $[12,13]$. Here, we report analysis of the immune-inducible transcriptome of E. tenax maggots, collected from storage pits of liquid manure. This enabled identification of genes encoding novel proteins that are potentially involved in pathogen-recognition and immune signaling. In addition, we identified numerous potential antimicrobial peptides that most probably contribute to the observed immune defense that is obviously important to control the wide array of pathogens present in the habitat of Eristalis larvae.

\section{Results and discussion}

Subtracted cDNA library of immune challenged E. tenax larvae

We observed a significant $E$. coli inhibitory activity of hemolymph samples from untreated E. tenax larvae that further increases upon immune challenge (Fig. 1). In order to construct a subtracted cDNA library enriched in immune-inducible genes we used purified RNA from LPS injected and untreated animals combined with a PCRbased SSH method. To induce strong and broad immune responses we injected a commercially available purified LPS preparation, which is known to contain impurities like nucleic acids, proteins and peptidoglycans, and which according to the supplier is commonly used as elicitor of immune responses in vertebrates and invertebrates. In order to confirm that the subtraction process has been performed efficiently, we analyzed the abundance of transcripts for the house-keeping gene $\alpha$-tubulin and for two genes, the Et-AMP10 and eristalin. The latter ones were found in the present study to be induced in response to

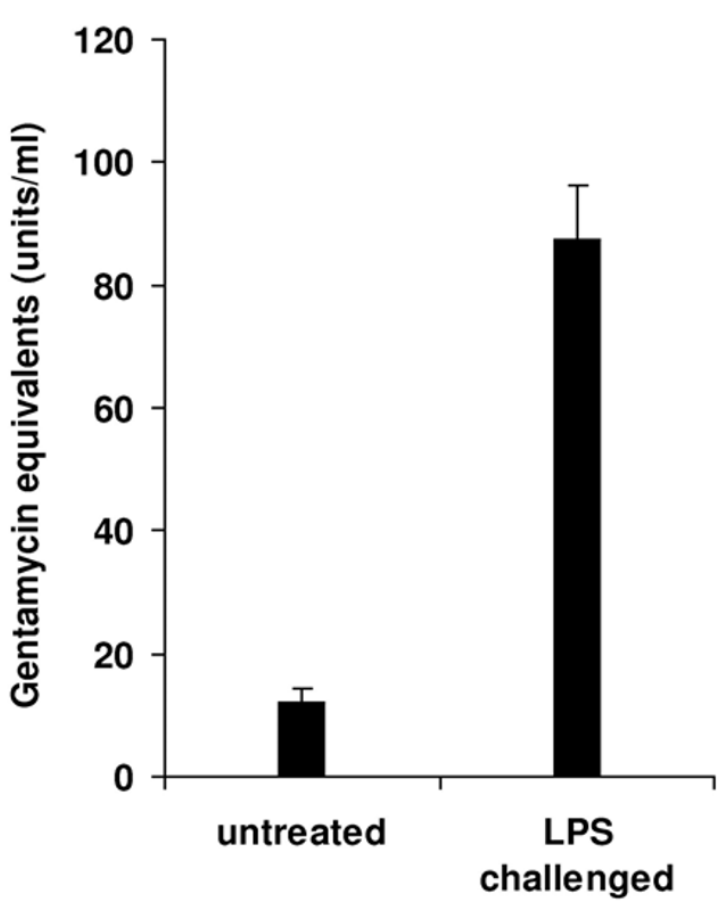

Figure I

Immune challenge of rat-tailed maggots of $E$. tenax induces the production of antimicrobial effector molecules. Antibacterial activities represented by gentamycin equivalents of hemolymph from untreated and LPS injected larvae are shown. Results represent mean values of independent determinations \pm S.D. 
immune challenge in Eristalis. Quantitative real-time PCR analyses revealed that transcripts of $\alpha$-tubulin were reduced 18 fold, whereas transcripts of Et-AMP10 and eristalin were enriched for 4 and 38 fold, respectively (Fig. 2 ). This is in agreement with values from the protocols of the manufacturer and indicates successful subtraction of the cDNA library. A total of 288 clones were randomly picked and subjected to colony PCR. Plasmids of $117 \mathrm{col}-$ onies that were positively screened in blot hybridization, indicating induced expression in response to LPS challenge, were isolated and sequenced. The sequences obtained (summarized in table 1) were deposited at EMBL European Bioinformatics Institute, and compared to databases of the National Center for Biotechnology Information using the program BLASTX. InterProScan at the EMBL European Bioinformatics Institute was used for an integrated search in PROSITE, Pfam and PRINTS databases in order to predict conserved motifs, signal sequences and transmembrane regions.

We describe here the identification of immune-inducible proteins in E. tenax that are potentially involved in recog-

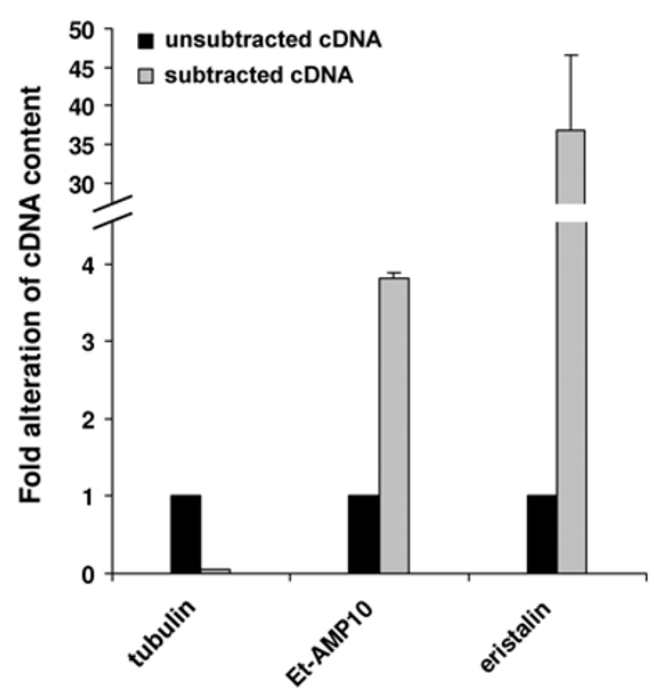

\section{Figure 2}

Confirmation of the enrichment of immune-related transcripts in the subtracted CDNA library by quantitative real-time PCR analysis. The relative amount of cDNAs of $\alpha$-tubulin, Et-AMPI0, and eristalin in the subtracted cDNA library (gray bars) is shown relative to their amount in unsubtracted cDNA library (black bars). The cDNA amount of the house-keeping gene $\alpha$-tubulin was reduced about 18 fold by the subtraction procedure. In contrast, potentially immunity-related genes Et-AMPIO and eristalin were found to be 4 and 38 fold enriched in the subtracted cDNA library, respectively. Results represent mean values of three independent determinations \pm S.D. nition of microbes, immune-related signaling, and antimicrobial effector mechanisms.

\section{Sensing of infection}

Innate immunity depends on pathogen recognition that is mainly mediated by host proteins called pattern recognition receptors. In insects, two prominent members, the Gram-negative binding proteins (GNBP) and peptidoglycan recognition proteins (PGRP) are involved in the activation of prophenoloxidase cascade and of Toll/IMD pathways resulting in the massive production of immune effector molecules [6]. Here, we identified transcripts of a protein that shares sequence similarities with PGRP-SB1 from several Drosophila species (Fig. 3A). This peptidoglycan recognition protein (PGRP) is one of a battery of pattern recognition proteins in insects that are essential for recognition of invading microbes and induction of immune responses [14]. Drosophila and Anopheles have 13 and 7 PGRP genes that are transcribed into at least 17 and 9 proteins, respectively [14]. Mammals possess a family of 4 PGRPs that function as both recognition proteins and effector molecules exhibiting bactericidal activities [15]. A Bayesian protein tree (Fig. 3B) was generated with sequences from Eristalis, humans, D. melanogaster, and A. gambiae and revealed that Eristalis PGRP groups nearest to Drosophila PGRP-SB1.

\section{Signaling}

We identified a protein sharing highest similarity with the relish protein of Glossina morsitans morsitans (Uniprot: AAZ91474). Relish or Nuclear factor (NF)-kappa-B p110 subunit is a key molecule of the Imd pathway and is phosphorylated by LPS-activated I-kappa-B kinase complex before being cleaved [16]. The Relish-p110 subunit is cleaved within seconds after immune challenge into Relish-p49 and Relish-p68 subunits. The latter translocates into the nucleus and activates the transcription of numerous immune-related genes [6]. The NF-kappa-B/I-kappa-B signaling pathways are evolutionarily well conserved and widely distributed among the animal kingdom [17].

Many serine proteinase inhibitors have evolved in vertebrates and invertebrates to regulate vital serine proteinase cascades. These contribute to melanization and host defense responses in insects $[18,19]$ as well as to hemostasis, fibrinolysis, and complement system in vertebrates $[20,21]$. Here, we identified one proteinase inhibitor that belongs to kazal-type serine proteinase inhibitors. Kazal domains are characterized by a well-preserved amino acid sequence containing three disulfide bridges, and display varying specificity for serine proteinases [22].

One identified cDNA encodes a protein that exhibits highest sequence similarities to the replicase polyprotein of the Drosophila $C$ virus. This virus belongs to the picornavi- 

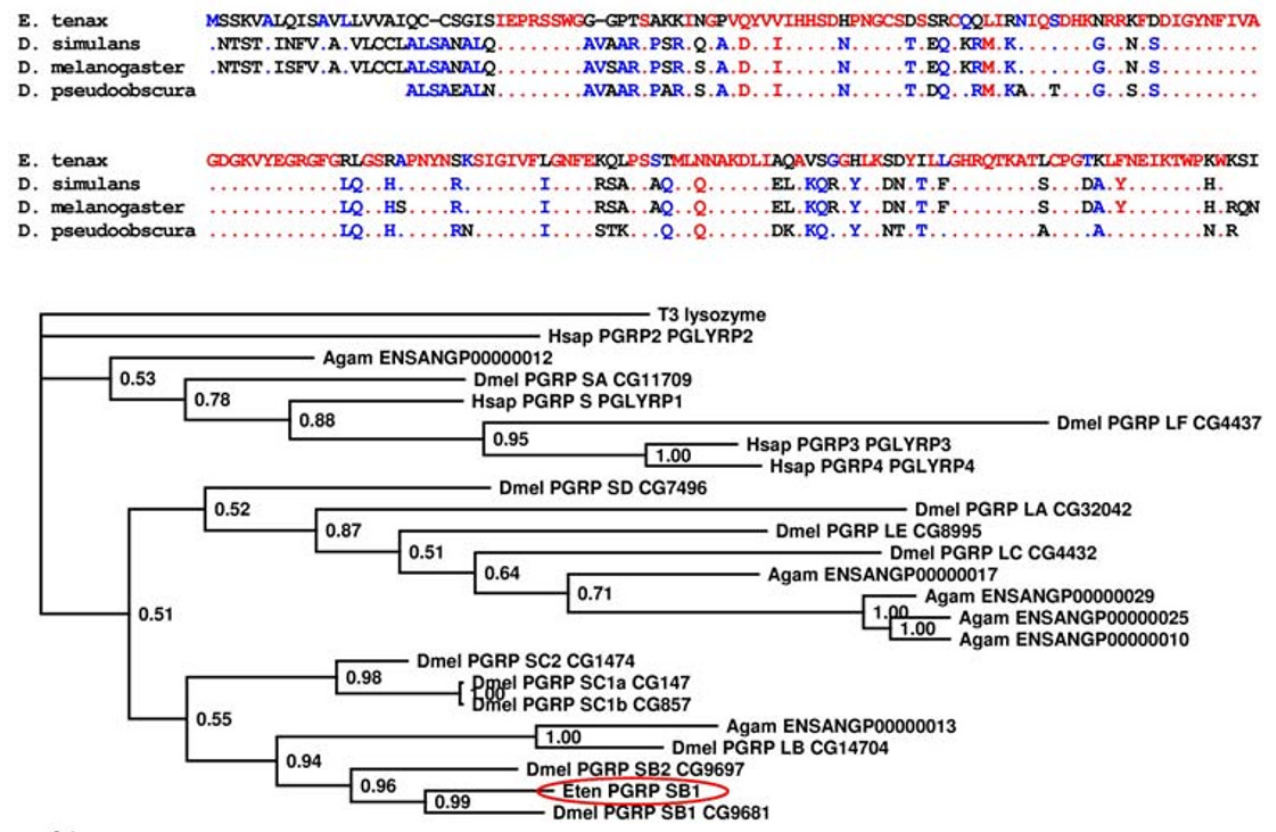

Figure 3

E. tenax PGRP is homologous to PGRP-SB I from Drosophila. (A) BlastP search with E. tenax PGRP-SBI sequence resulted in similar sequences from several Drosophila species and the differences are indicated in the alignment. Red color indicates $90 \%$ and blue color $50 \%$ consensus. The amino-terminal 24 amino acids represent a putative signal sequence. Accession numbers of PGRP-SBI proteins are: E. tenax, AM7064I6; D. simulans, Q70PX8; D. melanogaster, Q70PY2; D. pseudoobscura, Q29DT4. (B) A Bayesian protein tree was generated using the sequence of Eristalis PGRP (Eten PGRP SBI, indicated by a red circle) and sequences of human (Hsap PGRPs), D. melanogaster (Dmel PGRPs), and A. gambiae PGRPs (Agam ENSANGPs) and we found that Ersitalis PGRP grouped nearest to Drosophila PGRP-SBI. T3 lysozyme (N-acetylmuramoyl-L-alanine amidase, P2033I) of the bacteriophage T3 was used as out-group. The scale bar represents the substitutions per site according to the model of amino acid evolution applied.

rus family (enveloped single-stranded RNA viruses) that also includes the prominent polio and foot-and-mouth disease viruses [23]. However, it should be mentioned here that the similarities between the sequences depends mainly on a dsRNA-binding domain-like region. This region is also present in a variety of cellular RNA-binding proteins with different structures and diverse functions including e.g. the human interferon-induced protein kinase [24].

\section{Protein biosynthesis and cell proliferation}

We identified several transcripts of factors potentially involved in Eristalis protein biosynthesis including ribosomal proteins S8 and L6, lysyl-tRNA synthetase, and the translation initiation factor eIF5c. This is reasonable, since the massive production of antimicrobial peptides upon immune challenge depends on the activation of the cellular translation machinery in cells and tissues of the immune system $[9,13,25]$. Nevertheless, one important study reported the antibacterial activity of ribosomal pro- tein L1 fragment of Helicobacter pylori [26]. Additionally, Park et al. [27] found that lysyl-tRNA synthetase was secreted from intact human cells as a signaling molecule to trigger proinflammatory response by binding to macrophages and peripheral blood mononuclear cells to enhance their migration and the production of TNF- $\alpha$. Since lysyl-tRNA synthetase is highly conserved in evolution it is possible that it also serves as a signaling molecule in insects.

One transcript shared high sequence similarities with the evolutionarily conserved cellular repressor of E1A-stimulated genes (CREG). A finely-tuned balance exists between cell proliferation, cell division arrest, and apoptosis in the vertebrate immune response, and this may also be true for insects. CREG is a secreted glycoprotein that inhibits cell proliferation and enhances cell differentiation $[28,29]$. In humans, CREG was shown to bind to the cation-independent mannose 6-phosphate/insulin-like growth factor II receptor, and this receptor has been shown to be 
Table I: cDNAs from the subtracted $E$. tenax library

\begin{tabular}{|c|c|c|c|c|}
\hline Cluster & EMBL accession No. & Highest BLASTX match & PFAM & E value \\
\hline \multicolumn{5}{|c|}{ Protein biosynthesis } \\
\hline & AM706409 & Ribosomal protein S8 (Culicoides sonorensis) & PF0I20I & 7e-09 \\
\hline & AM706410 & Ribosomal protein L6 (D. melanogaster) & PF0II59 & $3 e-37$ \\
\hline & AM7064II & Lysyl-tRNA synthetase (D. melanogaster) & PF00I52 & $6 e-111$ \\
\hline & $\overline{\mathrm{AM} 706412}$ & elF5c (D. melanogaster) & PF02020 & $8 e-84$ \\
\hline \multicolumn{5}{|c|}{ Repression of cell proliferation } \\
\hline & AM706413 & CREG (D. melanogaster) & & $3 e-46$ \\
\hline \multicolumn{5}{|c|}{$\alpha$-tubulin-like protein } \\
\hline & AM7064I4 & AlphaTub85E (D. melanogaster) & PF03953 & $5 e-18$ \\
\hline \multicolumn{5}{|c|}{ dsRNA-binding domain-like protein } \\
\hline & $\underline{A M 706415}$ & Replicase polyprotein (Drosophila C virus) & PF00035 & $5 e-05$ \\
\hline \multicolumn{5}{|c|}{ Pattern recognition protein } \\
\hline & AM706416 & PGRP-SBI (D. melanogaster) & PFOI5IO & $6 e-64$ \\
\hline \multicolumn{5}{|c|}{ Signal transduction } \\
\hline & AM706417 & Relish (Glossina morsitans morsitans) & PF00023 & $7 e-35$ \\
\hline & AM706418 & Protein kinase (D. melanogaster) & & 5.2 \\
\hline \multicolumn{5}{|c|}{ Kazal-type serine protease inhibitor } \\
\hline & AM706419 & enhancer of split ml protein (D. simulans) & PF00050 & $4 e-07$ \\
\hline \multicolumn{5}{|c|}{ Putative antimicrobial peptides } \\
\hline Et-AMPI & AM706420 & Defensin (Phlebotomus duboscqi) & PFOI097 & $3 e-12$ \\
\hline Et-AMP2 & AM706421 & Bactenecin-7 (Bos taurus) & & 0.96 \\
\hline Et-AMP3 & $\overline{\mathrm{AM} 706422}$ & Tachycitin (Tachypleus tridentatus) & PF0I607 & $3 e-06$ \\
\hline Et-AMP4 & $\overline{\mathrm{AM} 706423}$ & Salivary protein SG3 (Anopheles stephensi) & & $7 e-15$ \\
\hline Et-AMP5 & AM706424 & $\alpha$-helical cecropin-like & & NSMI \\
\hline Et-AMP6 & AM706425 & Ser/Thr/Lys-rich putatively disulfide bridged & & NSM \\
\hline Et-AMP7 & AM706426 & Putatively disulfide bridged peptide with a pl 10,5 & & NSM \\
\hline Et-AMP8 & $\overline{\mathrm{AM} 706427}$ & Putatively disulfide bridged peptide with a pl 10,3 & & NSM \\
\hline Et-AMP9 & AM706428 & Putatively disulfide bridged peptide with a $p / 9,3$ & & NSM \\
\hline Et-AMPIO & AM706429 & Putatively disulfide bridged anionic peptide & & NSM \\
\hline Et-AMPII & $\overline{\mathrm{AM} 706430}$ & Glycine-rich peptide I & & NSM \\
\hline Et-AMPI2 & AM706431 & Glycine-rich peptide 2 & & NSM \\
\hline Et-AMPI3 & AM706432 & Glycine-rich peptide 3 & & NSM \\
\hline Et-AMPI4 & $\overline{\mathrm{AM} 706433}$ & Glycine-rich peptide 4 & & NSM \\
\hline Et-AMPI5 & AM706434 & Linear peptide I & & NSM \\
\hline Et-AMPI6 & $\overline{\mathrm{AM} 706435}$ & Linear peptide 2 & & NSM \\
\hline Et-AMPI7 & AM706436 & Linear peptide 3 & & NSM \\
\hline Et-AMPI8 & AM706437 & Linear peptide 4 & & NSM \\
\hline Et-AMPI9 & AM706438 & Linear peptide 5 & & NSM \\
\hline
\end{tabular}

'NSM, no significant match

required for CREG-induced growth suppression. In insects, CREG has been shown to be expressed in adult female salivary glands of A. gambiae [30].

We found one transcript that exhibits similarity to the carboxyl terminus of $\alpha$-tubulin from other organisms. Although $\alpha$-tubulin is a major constituent of microtubules and a well-known housekeeping gene, many genes and pseudogenes exist that form the $\alpha$-tubulin superfamily [31]. Induction of $\alpha$-tubulin-like mRNA after immune challenge has also been observed in leech [25], and another study demonstrated that the dengue virus 2 directly binds to a $48 \mathrm{kDa}$ tubulin or tubulin-like protein of C6/36 mosquito cells [32]. These results suggest that at least some $\alpha$-tubulin-like proteins may be involved in immune responses. However, in this study $\alpha$-tubulin itself was depleted by the subtraction process (Fig. 2) suggesting that it is not immune-induced and the identified sequence may be derived from a pseudogene or related isoform.

\section{Effector molecules}

The most striking finding among the genes inferred to be up-regulated in response to septic injury is the identification of numerous putative antimicrobial peptides in $E$. tenax. Defensins have been found in a variety of animals and plants [33-35] and even in the fungus Pseudoplectania nigrella [36], which is suggestive for an evolutionarily conserved role in innate immunity. In agreement, we identified an E. tenax defensin that we named eristalin. Eristalin contains a predicted signal and pro-sequence and shares 


\begin{tabular}{|c|c|c|}
\hline $\mathbf{E}$. & tenax & ATCDLLSFLNVKDAACAAHCLAKGYRGGYCDGRKVCNCRR \\
\hline P. & terraenovae & . . . . . GTGINHS . . . . . LR.N. . . .N.KG. .V. .N \\
\hline S. & peregrina_1 & . .IR.N. . . .N.KA. .V. .N \\
\hline & domestica & $\ldots \ldots$. GTG.GHS . . . . LR.N. . . .N.KG. .V. .N \\
\hline & eregrina_2 & . . . . . GIG.QHS . .I. .VFR.N. . . .T.KGI.V. .N \\
\hline & boscqi & $\ldots \ldots$. AFG.GH. . . . . IGH . . . . . NSKA. . T. . \\
\hline & gypti_1 & . . . . . GFG.G.S . . . . I.R.N. . . NSK. . V. .N \\
\hline & gypti_2 & . . . . . GFG.G.S . . . . I.R.N. . . NSQ . .V. .N \\
\hline & egypti_3 & . . . . . GFG.G.S . . . . I.RRN . . . NAK. . V. .N \\
\hline & mbiae & . . . . A.GFG.GSSL . . . . I.RR. . . . . NSKA. .V. .N \\
\hline & & . .I.RR. . . . .NSKA. .V. .N \\
\hline & biensis & . . . . A.GFG.GSSL . . . I.RR. . \\
\hline & ensis & .....T.GT.IGSS. \\
\hline & anogaster & . . . . . . KW. WNHT . . G. . I . . FK . . . NDKA. .V. . N \\
\hline & ans & . . . . . KW.WNHT . . G. . I. . FKK. . . NDKA. .V. .N \\
\hline & trans_2 & $\ldots \ldots$. . MW. . NHS . . . . . IL.KS . R.NDDA. .V. . K \\
\hline & itrans_1 & $I \ldots \ldots I$ \\
\hline
\end{tabular}

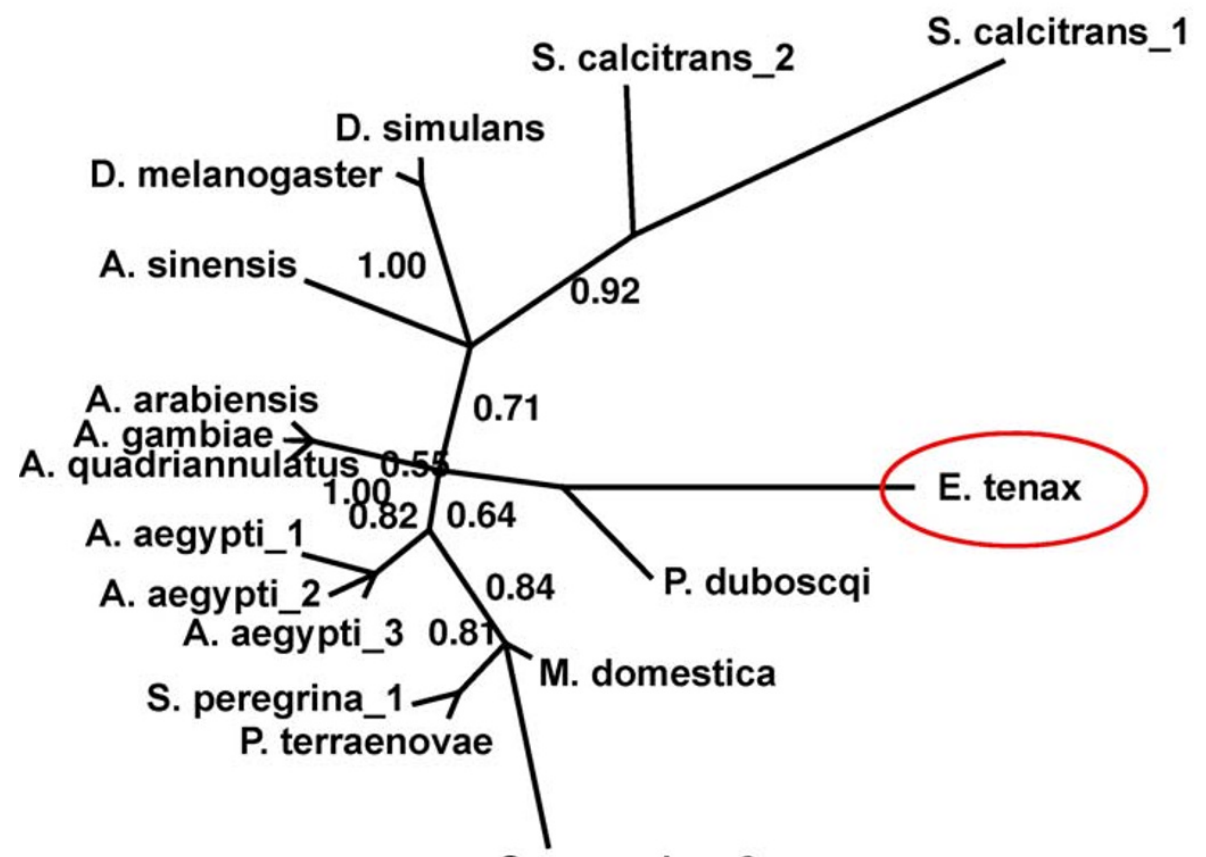

S. peregrina_2

0.1

\section{Figure 4}

Sequence alignment of eristalin with other dipteran defensins. (A) Eristalin was aligned with other dipteran defensins. For clarity only sequences of mature defensins were used for alignment. Red color indicates $90 \%$ and blue color $50 \%$ consensus. (B) A Bayesian protein tree was generated and we found that eristalin, defensin_I and defensin_2 of Stomoxys calcitrans, and defensin_I of Sarcophaga peregrina show some higher deviation in sequence when compared to other dipteran defensins. Accession numbers of defensins are (from top to bottom): AM706420, PI089I, PI83 I3, Q86BUI, P3 I530, P83404, P9I793, P8I602, P8I603, Q17027, Q38L94, Q38LEI, Q4ZJJ8, P36192, Q86BW0, OI6I37, OI6I36. The scale bar represents the substitutions per site according to the model of amino acid evolution applied. 


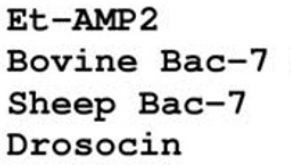

\section{NPAARNHLP-PQGP SWPRPGP STWPRPGP STWPRPGPFS-PSTGPF-NPNPRP IHF RRIRPR-PPRLPRPRPRPLPFPRPGPRP IPRPLPFPRPGPRP IPRPLPFPRPGPRPIPRPL LRPR-RPRLPRPRPRPRPRPRSLPLPRPQPRRIPRP ILLPWRPPRP IPRPQPQP IPRWL GKPRPYS---PRPTSHPRPIRV}

\section{Figure 5}

Sequence alignment of Et-AMP2 with Drosophila drosocin along with bactenecin-7 from sheep and bovine. For clarity only sequences of mature peptides of ET-AMP2 (AM70642I), bactenecin-7 from sheep (UniProt: P504I5) and bovine (UniProt: P1966I), and of drosocin (UniProt: P36193) are shown. The predicted signal sequence of Et-AMP2 was omitted.

sequence similarities to other insect defensins (Fig. 4A). In addition, our phylogenetic analysis using sequences of eristalin and other defensin sequences from dipterans suggests that the defensins of E. tenax, S. peregrina, and S. calcitrans are more deviated in sequence. Maggots of all three of this species live on feces (Fig. 4B) suggesting that independent occupation of such 'extreme' ecological niches is accompanied by divergent evolution of immune-related effector molecules.

The putative antimicrobial peptide Et-AMP2 shares highest similarities to bactenecin-7 (Fig. 5) a cathelicidinderived antimicrobial peptide of bovine neutrophil granules that exhibits antibacterial activity predominantly against gram-negative bacteria [37]. Bactenecin-7 belongs to the Pro/Arg-rich antibiotics [38] which also include porcine PR-39 [39], insect drosocin, abaecin, and lebocin [40]; however, no homologues were identified in humans. The antibacterial effects of Pro/Arg-rich peptides are likely due to an impaired function of the respiratory chain and of energy-dependent activities in the inner membrane of susceptible microorganisms [41].

ET-AMP3 shows high similarity to the antimicrobial tachycitin of the horseshoe crab [42] and ET-AMP4 to the salivary protein SG3, with as yet unknown function, from Anopheles stephensi [43]. Et-AMP5 is a cationic peptide with putative $\alpha$-helical content and with similarities to cecropins or to antimicrobial cathelicidin-derived peptides like bovine BMAP-27 [44]. Et-AMP6, 7, 8, and 9 are putatively disulfide-bridged cationic peptides, while EtAMP10 is a putatively disulfide bridged anionic peptide. None share similarities with any known proteins or peptides but all exhibit Lys/Arg clusters in the proximity of hydrophobic clusters; this is typical for many antimicrobial peptides [4].

We also identified four isoforms (Et-AMP11 to 14) of glycine-rich peptides with a glycine content of over 20\% (Fig. $6)$. The list of glycine-rich antimicrobial peptides is rapidly growing and includes prominent members like the antifungal holotricin-3 from the chafer Holotrichia diomphalia [45], the antibacterial acanthoscurrin from the spider Acanthoscurria gomesiana [46], and the antibacterial armadillidin from the crustacean Armadillidium vulgare [47]. Interestingly, the observation that several isoforms of a glycine-rich peptide are present in a single organism is in agreement with the identification of infectioninduced glycine-rich peptides in C. elegans [48] and of putative glycine-rich attacins in the lepidopteran Antherea mylitta [49]. Similarly, we identified five isoforms (EtAMP15 to 19) of a linear peptide that are cationic with a glycine content of over $10 \%$ and share sequence similarities to the carboxyterminal half of bacterial outer-membrane porins and to a putative antimicrobial peptide from the bug Riptortus clavatus [50] (Fig. 7).

\section{Quantitative real time RT-PCR analysis}

In order to precisely determine the immune-induction of genes identified in the present study we used quantitative

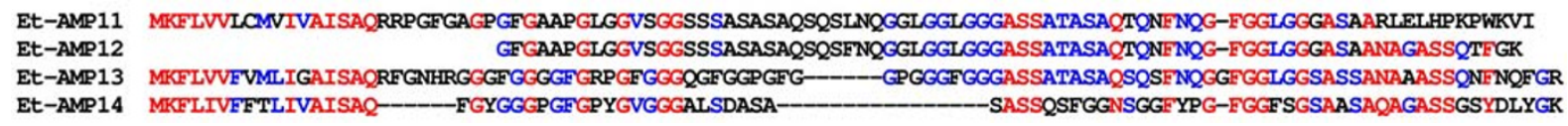

Figure 6

Sequence alignment of the glycine-rich peptides Et-AMP I I, I 2, I3, and I 4. Sequences of the glycine-rich peptides Et-AMPII, I2, I3, and I4 (AM706430 to AM706433) were aligned. The alignment suggests that the isoforms have most probably been evolved by gene duplication and evolutionary selection to target a variety of pathogens. The amino-terminal I 7 amino acids represent a predicted signal sequence. The amino-terminal end of Et-AMPI 2 is not complete. 


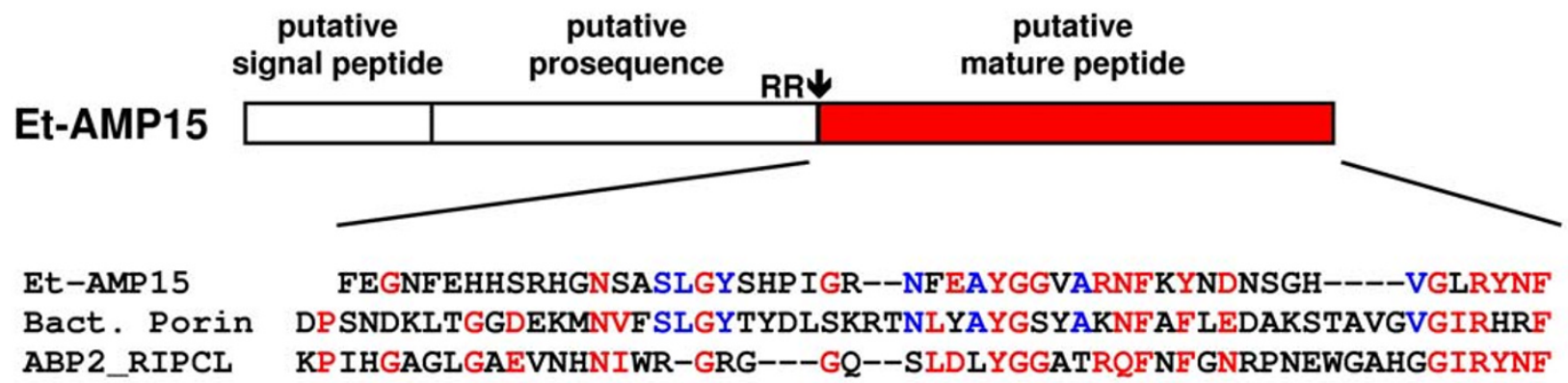

Figure 7

Sequence alignment of the linear peptide Et-AMP I 5 with a bacterial porin and a putative antimicrobial peptide from Riptortus clavatus. The linear peptide Et-AMPI5 (AM706434) is schematically drawn, showing predicted signal peptide, propeptide, and mature peptide. The mature peptide exhibits some sequence similarities with the carboxy-terminal part of bacterial porin from Bordetella parapertussis (Bact. Porin, UniProt: Q7W5A6) and a putative antimicrobial peptide from the bug $R$. clavatus (ABP2_RIPCL, UniProt: Q27906).

real-time RT-PCR analysis. The Eristalis defensin eristalin and the putatively disulfide-bridged anionic peptide EtAMP10 were 14 and 34 fold, respectively, up-regulated upon LPS injection (Fig. 8). The determined induction levels are in a similar range as reported for defensins from other insects [51]. In contrast, the expression of the housekeeping genes actin and tubulin were not influenced by the treatment.

\section{Conclusion}

In the present study we analyzed the immune-inducible transcriptome from rat-tailed maggots of the drone fly $E$. tenax which have evolved the ability to survive in stagnant, frequently anaerobic aquatic habitats with extreme microbial contamination [3]. Survival in environments with such a strong microbial stress obviously depends on an innate immune system that has been adapted specifically to this ecological niche.

To date, seven distinct antimicrobial peptides have been reported from Drosophila, including the antifungal peptides drosomycin and metchnikowin, and five antibacterial peptides: attacin, cecropin, defensin, diptericin and drosocin [40]. Recently, genome-wide studies with Drosophila, Anopheles, and Aedes reveal that intracellular components of immune signaling pathways are conserved among Diptera [8]. In accordance, we identified potential counterparts in E. tenax that mediate non-self recognition (e.g. PGRP) or immune-related signaling (e.g. relish) in Drosophila and Anopheles. However, genome-wide studies also elucidate differences between both dipterans, particularly in potential extracellular components of the Toll pathway and in effector molecules including antimicrobial peptides [8]. In agreement, we identified numerous putative antimicrobial peptides in E. tenax that have obvi- ously no homologues in D. melanogaster, A. gambiae, or A. aegypti. In total, we found 19 putative antimicrobial peptides some of which show sequence similarities to antimicrobial defensins, bactenecin-7, or tachycitin. 16 peptides are of novel-type including four isoforms of a glycine-rich peptide and five isoforms of a linear peptide. The isoforms may have been evolved by gene duplication and evolutionary selection to target a variety of pathogens, probably in a similar manner to that described for the six $\alpha$ defensins and four $\beta$-defensins from humans [52].

Interestingly, we observed a significant $E$. coli inhibitory activity of hemolymph samples from untreated E. tenax larvae. This was not normally the case with hemolymph samples from other insect species that we analyzed in our laboratory (e.g. Thermobia domestica [9], Galleria mellonella [10], and Tribolium castaneum). This significant (probably constitutive) expression of antimicrobial peptides might be caused by the uptake of food with a high bacterial load. Recently, it has been demonstrated that Drosophila gut cells are able to sense bacteria-contaminated food which induces epithelial immune responses [6]. Thus, there may be an even richer assembly of immunity-related genes in Eristalis that would not be detected by our SSH approach.

Future work will include chemical or recombinant production of the identified peptides in order to analyze their specific activities against viruses, bacteria, fungi, or protozoa. Currently, we are investigating the potential of EtAMP10 and eristalin to confer resistance against phytopathogens in transgenic plants similar as recently shown for the antifungal peptide gallerimycin from the greater wax moth Galleria mellonella [53]. In addition, the identified genes may help to elucidate divergent evolution of antimicrobial peptides in Diptera and the interdepend- 


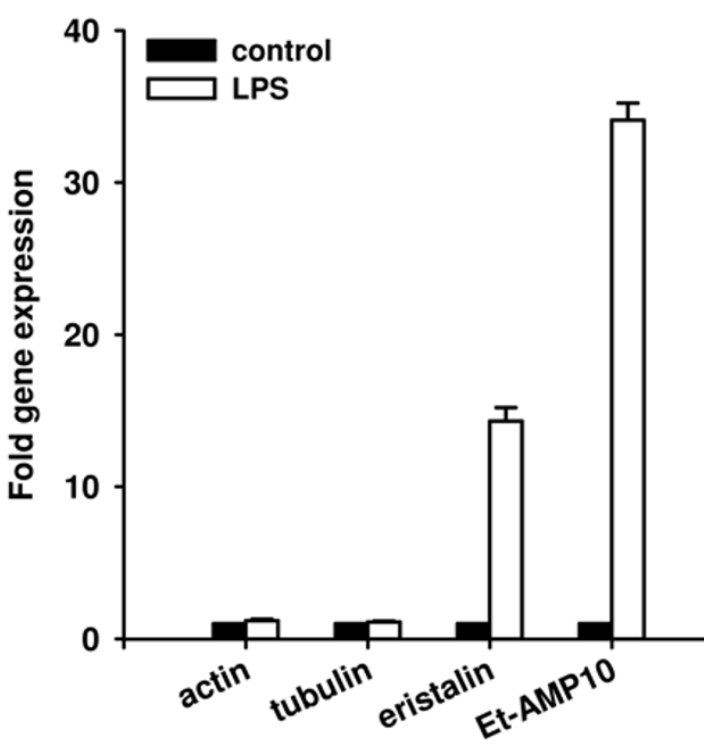

Figure 8

Quantitative real time RT-PCR analysis of transcriptional levels of selected genes in immune challenged and untreated larvae. The mRNA levels of selected genes in immune challenged animals (black bars) were determined and are shown relative to their expression levels in untreated animals (white bars). The transcriptional rates of eristalin and ET-AMPIO were found to be increased over 14 and 34 fold, respectively, in response to LPS injection. In contrast, the amount of actin and $\alpha$-tubulin transcripts were not significantly influenced. Results represent mean values of three independent determinations \pm S.D.

ence between ecological adaptation and insect immune defenses.

\section{Methods}

\section{Insects}

Rat-tailed maggots were collected in liquid manure pits at cattle farms near Giessen (Hessen) and the village Siewisch (Brandenburg), Germany. Using a practicable key for determination of hoverfly larvae [54], we identified third instar larvae of the drone fly E. tenax. As typical characters we observed the lack of setae along the lower lateral margins and the last pair of prolegs with most of the large primary crochets facing towards the lateral margins of the body. Identification was confirmed by determination of adults which hatched at the end of October 2005.

\section{Immune challenge of larvae and isolation of hemolymph and $m R N A$}

Last instar E. tenax larvae, each weighing between 200$300 \mathrm{mg}$, were used for immune-challenge. $10 \mu \mathrm{l}$ sample volume, corresponding to $100 \mu \mathrm{g}$ LPS (purified Escherichia coli endotoxin 0111:B4, Cat. No.: L2630, Sigma, Taufkirchen, Germany) per larva were injected dorsolaterally into the hemocoel using $1 \mathrm{ml}$ disposable syringes and $0.4 \times 20 \mathrm{~mm}$ needles mounted on a microapplicator. For antibacterial activity assays, hemolyph samples were isolated by bleeding injected larvae $24 \mathrm{~h}$ post challenge or untreated larvae into plastic tubes. Total RNA was extracted from whole larvae $8 \mathrm{~h}$ post injection using the TriReagent isolation reagent (Molecular Research Centre, Cincinnati, Ohio, USA) and a further poly-(A)+ RNA preparation was performed using a mRNA Nucleotrap kit (Macherey Nagel, Germany) according to the instructions of the manufacturers. RNA integrity was confirmed by ethidium bromide gel staining and quantities were determined spectrophotometrically [55].

\section{Antibacterial activity assay}

Antibacterial activity of hemolymph samples was measured by an inhibition zone assay using a LPS-defective, streptomycin- and ampicillin-resistant mutant of Escherichia coli K12 strain D31 [56]. In brief, Petri dishes $(\varnothing 100 \mathrm{~mm})$ were filled with $7 \mathrm{ml}$ E. coli suspension, containing $2 \times$ YT-nutrient broth (Roth, Karlsruhe, Germany), $1 \%$ high-purity agar-agar (Roth), and $2 \times 10^{4}$ viable bacteria in logarithmic growth phase. Holes with a diameter of $4 \mathrm{~mm}$ were punched into the agar and filled with $3 \mu \mathrm{l}$ of cell-free hemolymph. The diameters of the clear zones were measured after $24 \mathrm{~h}$ of incubation at $37^{\circ} \mathrm{C}$ and units/ $\mathrm{ml}$ were calculated using a calibration curve obtained with dilutions of gentamycin (Sigma).

\section{Construction of a subtracted cDNA library using the $\mathrm{SSH}$ method}

In order to identify differentially expressed genes during immune response the SSH method was performed using mRNAs from immune challenged and control larvae and the PCR-Select cDNA Subtraction Kit from Clontech (Mountain View, CA, USA), according to the protocol of the manufacturer. Briefly, $1 \mu \mathrm{g}$ of purified mRNA from immune-challenged and control larvae were reverse transcribed into cDNA using a cDNA synthesis primer, subsequently double stranded cDNA was generated and digested with RsaI. The double stranded cDNA from immunized larvae was ligated in separate aliquots to adaptor 1 or adaptor $2 \mathrm{R}$ and were denaturated at $98^{\circ} \mathrm{C}$ for $90 \mathrm{~s}$ and then hybridized at $68^{\circ} \mathrm{C}$ for $8 \mathrm{~h}$ with a 30 fold excess of double stranded cDNA from control larvae. Subsequently, both samples were mixed together again with a 10 fold excess of freshly denaturated double stranded cDNA from control larvae and hybridized in one tube at $68^{\circ} \mathrm{C}$ for $16 \mathrm{~h}$. The sample was then subjected to two rounds of suppression PCR with PCR-primer 1 and nested primers supplied with the kit. PCR amplifications were performed in a total volume of $25 \mu \mathrm{l}$ using a PCR cycler (Biometra, Göttingen, Germany) with a heated lid and the 
Advantage PCR system (Promega, Mannheim, Germany). An initial adapter extension at $72^{\circ} \mathrm{C}$ for 5 min was followed by a denaturation step at $95^{\circ} \mathrm{C}$ for $1 \mathrm{~min}$ and by 27 cycles of denaturation at $95^{\circ} \mathrm{C}$ for $15 \mathrm{~s}$, annealing at $66^{\circ} \mathrm{C}$ for $30 \mathrm{~s}$, and extension at $72^{\circ} \mathrm{C}$ for $90 \mathrm{~s}$. A final 7 -min $72^{\circ} \mathrm{C}$ step was added to allow complete extension of the products. The secondary PCR was performed with nested primer 1 and $2 \mathrm{R}$ on the diluted primary PCR products for 12 cycles under same conditions, except that $68^{\circ} \mathrm{C}$ was used as annealing temperature. The subtraction efficiency was confirmed by quantitative real-time PCR of the actin gene of subtracted PCR products in comparison to not subtracted PCR products. Resulting PCR products of the secondary subtractive PCR were separated on $1 \%(\mathrm{w} / \mathrm{v})$ agarose gel electrophoresis with ethidium bromide staining, according to standard procedures [55] and five fractions were obtained by excising five gel pieces of PCR products with different lengths. Subsequently, PCR product fractions were separately purified using the NucleoSpin Extract II kit (Macherey Nagel), ligated into pGEM-T easy vector (Promega) and transformed into TOP10F' cells (Invitrogen, Carlsbad, CA, USA). The library was plated on $2 \times \mathrm{YT}$ agar plates containing $100 \mu \mathrm{g} / \mathrm{ml}$ ampicillin and incubated at $37^{\circ} \mathrm{C}$ for $16 \mathrm{~h}$. A preliminary screen of 15 colonies using the FastPlasmid Mini kit (Eppendorf, Hamburg, Germany) followed by EcoRI digestion of isolated plasmids and agarose gel electrophoresis showed that over $90 \%$ of clones contained an insert in the vector.

\section{Colony PCR and blot hybridization}

Colony PCR was performed on 288 randomly picked colonies with vector specific primers T7-promotor: 5'TAATACGACTCACTATAGGG-3' and SP6: 5'-ATTTAGGTGACACTATAG-3' (purchased from Thermo electron, Waltham, MA, USA) using a Biometra PCR cycler and the Red Taq PCR system (Sigma, Taufkirchen, Germany). Used PCR conditions were: denaturation at $95^{\circ} \mathrm{C}$ for 3 min followed by 30 cycles of denaturation at $95^{\circ} \mathrm{C}$ for 15 $\mathrm{s}$, annealing at $43^{\circ} \mathrm{C}$ for $15 \mathrm{~s}$, and extension at $72^{\circ} \mathrm{C}$ for $60 \mathrm{~s}$. A final 7 -min $72^{\circ} \mathrm{C}$ step was added to allow complete extension of the products. $1 \mu \mathrm{l}$ of resulting PCR products were identically spotted onto two sheets of positively charged nylon membranes (Roche, Lewes, United Kingdom). Membranes were dried and UV cross-linked using a BioRad UV cross-linker (BioRad, München, Germany), according to the instructions of the manufacturer. Digoxigenin labeled probes for hybridization were generated using secondary PCR products of subtracted and non-subtracted cDNAs and the Dig-High Prime Labelling kit (Roche, Lewes, United Kingdom). Hybridization, washing, and detection of digoxigenin labeled DNA was performed in accordance to the user guide instructions of the Dig Easy Hyb Granules, Dig-Wash and Block Buffer Set, Anti-Digoxigenin-AP and NBT/BCIP ready-to-use tablets (Roche).

\section{Sequencing and computer analysis of cDNA sequence data} Plasmid isolation of 117 positively screened colonies was performed with the FastPlasmid Mini kit (Eppendorf) and purified plasmids were custom sequenced by Macrogen Inc. (Seoul, South-Korea). Sequences were used to identify similar sequences of the National Center for Biotechnology Information databases using BLASTX program (BLASTX 2.2.13; http://www.ncbi.nlm.nih.gov/BLAST/). InterProScan http://www.ebi.ac.uk/InterProScan/ was used for an integrated search in PROSITE, Pfam, and PRINTS databases at EMBL-European Bioinformatics Institute and to predict signal sequences and transmembrane regions.

\section{Sequence alignments and phylogenic analyses}

Sequence alignments were computed using the blosum 62 algorithm [57] at http://bioinfo.genopole-toulouse.prd.fr. For phylogenetic reconstruction, we used the software package MrBayes 3.1.2 [58], which combines Bayesian inference and Markov chain Monte Carlo convergence acceleration techniques known as Metropolis coupling. The best fixed-rate model of amino acid evolution was determined by model jumping among nine possible models. The model with the overall highest posterior probability was WAG [59] for PGRPs and Blosum62 model [60] for defensins. Generations were sampled with the current tree saved at intervals of 100 generations. We used convergence diagnostic (i.e., the standard deviation of split frequencies) to determine whether the run length was sufficient. The average standard deviation of split frequencies at $2 \times 10^{6}$ generations was 0.0076 for PGRPs and at $10^{7}$ generations 0.0023 for defensins, respectively. This therefore indicated that the two chains that were run converged on similar results. The $50 \%$ majority rule tree presented here was constructed from all sampled trees with the first $25 \%$ of all trees. Trees were visualized with TREEVIEW 1.6.6 [61]. Posterior probabilities plotted at the nodes can be interpreted as the probability that the tree or clade is correct [62].

\section{Quantitative real time RT-PCR}

Quantitative PCR was performed with the real-time PCR system Mx3000P (Stratagene, La Jolla, California, USA) using the FullVelocity SYBR ${ }^{\circledast}$ Green QRT-PCR Master Mix (Stratagene, La Jolla, California, USA), according to the protocols of the manufacturer. In order to confirm the subtraction efficiency of constructed cDNA library 1 ng of unsubtracted and subtracted CDNA, respectively, was used to amplify $\alpha$-tubulin, Et-AMP10, and eristalin. Used primers were: the universal primers $\alpha$-tubulin-forward: 5 'GCCAACCAGATGGTCAA-3' and $\alpha$-tubulin-reverse: 5 'GCTTGGTCTTGATGGTG-3', eristalin-forward: 5ATGGCTACATGTGATCTGCT-3', eristalin-reverse: 5'ACGGCAATTGCAGACT-3', Et-AMP10-forward: 5'ATGGACCCTCTTCTGTGG-3', Et-AMP10-reverse: 5'- 
TGGGCATCTGACAATA-3'. For gene expression analyses, we used $100 \mathrm{ng}$ total RNA per well and primers described above. In addition, insect universal primers actin-forward: 5'-ATCCTCACCCTGAAGTACCC-3 and actin-reverse: 5CCACACGCAGCTCATTGTA-3' were used to amplify Eristalis actin. Primers were selected using the primer3 software [63] and were purchased from Thermo electron (Waltham, MA, USA).

\section{Competing interests}

The author(s) declare that they have no competing interests.

\section{Authors' contributions}

BA designed and carried out the experiments, performed the analyses, and drafted parts of the manuscript. AV collected and immune challenged the animals, participated in the experimental design and coordination, and drafted parts of the manuscript. All authors read and approved the final manuscript.

\section{Acknowledgements}

We thank Meike Fischer for excellent technical assistance and Katja Altincicek, Christopher West Wheat, and Rod Snowdon for critical reading of the manuscript. The authors acknowledge financial support from the JustusLiebig-University of Giessen to BA and from the Deutsche Forschungsgemeinschaft to AV.

\section{References}

I. Grimaldi D, Engel M: Evolution of insects Cambridge University Press, New York; 2005.

2. Stahls G, Hippa H, Rotheray G, Muona J, Gilbert F: Phylogeny of Syrphidae (Diptera) inferred from combined analysis of molecular and morphological characters. Syst Entomol 2003 28:433-450.

3. Chapman D: Water Quality Assessments - A Guide to Use of Biota, Sediments and Water in Environmental Monitoring Second edition. University Press, Cambridge; 1996.

4. Zasloff M: Antimicrobial peptides of multicellular organisms. Nature 2002, 41 5:389-395.

5. Brahmachary M, Krishnan SP, Koh JL, Khan AM, Seah SH, Tan TW Brusic V, Bajic VB: ANTIMIC: a database of antimicrobial sequences. Nucleic Acids Res 2004:D586-589.

6. Lemaitre B, Hoffmann JA: The host defense of Drosophila melanogaster. Annu Rev Immunol 2007, 25:697-743.

7. Cherry S, Silverman N: Host-pathogen interactions in drosophila: new tricks from an old friend. Nat Immunol 2006 , 7:911-917.

8. Waterhouse RM, Kriventseva EV, Meister S, Xi Z, Alvarez KS, Bartholomay LC, Barillas-Mury C, Bian G, et al.: Evolutionary dynamics of immune-related genes and pathways in disease-vector mosquitoes. Science 2007, 3 I 6: 1738-1743.

9. Altincicek B, Vilcinskas A: Identification of immune-related genes from an apterygote insect, the firebrat Thermobia domestica. Insect Biochem Mol Biol 2007, 37:726-73I.

10. Seitz V, Clermont A, Wedde M, Hummel M, Vilcinskas A, Schlatterer $\mathrm{K}$, Podsiadlowski L: Identification of immunorelevant genes from greater wax moth (Galleria mellonella) by a subtractive hybridization approach. Dev Comp Immunol 2003, 27:207-2 I 5.

II. Zhu Y, Johnson TJ, Myers AA, Kanost MR: Identification by subtractive suppression hybridization of bacteria-induced genes expressed in Manduca sexta fat body. Insect Biochem Mol Biol 2003, 33:541-559.

12. Altincicek B, Vilcinskas A: Analysis of the immune-related transcriptome of a lophotrochozoan model, the marine annelid Platynereis dumerilii. Front Zool 2007, 4:18.
13. Huang G, Liu H, Han Y, Fan L, Zhang Q, Liu J, Yu X, Zhang L, Chen S, Dong $M$, Wang $L, X u A$ : Profile of acute immune response in Chinese amphioxus upon Staphylococcus aureus and Vibrio parahaemolyticus infection. Dev Comp Immunol 2007 3 I: 1013-1023.

14. Dziarski R: Peptidoglycan recognition proteins (PGRPs). Mol Immunol 2004, 40:877-886.

I5. Lu XF, Wang MH, Qi J, Wang HT, Li XN, Gupta D, Dziarski R: Peptidoglycan recognition proteins are a new class of human bactericidal proteins. J Biol Chem 2006, 28 I:5895-5907.

16. Silverman N, Zhou R, Stoven S, Pandey N, Hultmark D, Maniatis T: A Drosophila I kappa B kinase complex required for Relish cleavage and antibacterial immunity. Genes Dev 2000 I 4:246I-247I.

17. Wang XW, Tan NS, Ho B, Ding JL: Evidence for the ancient origin of the NF-kappa B/l kappa B cascade: Its archaic role in pathogen infection and immunity. Proc Natl Acad Sci USA 2006, 103:4204-4209.

18. Theopold U, Schmidt O, Soderhall K, Dushay MS: Coagulation in arthropods: defence, wound closure and healing. Trends in Immunol 2004, 25:289-294.

19. Kanost MR: Serine proteinase inhibitors in arthropod immunity. Dev Comp Immunol 1999, 23:291-301.

20. Hughes $A L$, Yeager M: Molecular evolution of the vertebrate immune system. Bioessays 1997, 19:777-786.

21. Pike RN, Buckle AM, le Bonniec BF, Church FC: Control of the coagulation system by serpins - Getting by with a little help from glycosaminoglycans. FEBS Journal 2005, 272:4842-485 I.

22. Laskowski M, Kato I: Protein inhibitors of proteinases. Annu Rev Biochem 1980, 49:593-626.

23. Cherry S, Perrimon N: Entry is a rate-limiting step forviral infection in a Drosophila melanogaster model of pathogenesis. Nature Immunol 2004, 5:81-87.

24. Burd CG, Dreyfuss G: Conserved structures and diversity of functions of RNA-binding proteins. Science 1994, 265:6I5-62I.

25. Lefebvre C, Cocquerelle C, Vandenbulcke F, Hott D, Huot L, Lemoine $Y$, Salzet M: Transcriptomic analysis in the leech Theromyzion tessulatum: involvement of cystatin $B$ in innate immunity. Biochem J 2004, 380:617-625.

26. Putsep K, Branden Cl, Boman HG, Normark S: Antibacterialpeptide from H-pylori. Nature 1999, 398:67I-672.

27. Park SG, Kim HJ, Min YH, Choi EC, Shin YK, Park BJ, Lee SW, Kim S: Human lysyl-tRNA synthetase is secreted to trigger proinflammatory response. Proc Natl Acad Sci USA 2005, 102:6356-636I.

28. Veal E, Eisenstein M, Tseng ZH, Gill G: A cellular repressor of E I A-stimulated genes that inhibits activation by E2F. Mol Cell Biol 1998, 18:5032-504I.

29. Sacher M, Di Bacco A, Lunin VV, Ye Z, Wagner J, Gill G, Cygler M: The crystal structure of CREG, a secreted glycoprotein involved in cellular growth and differentiation. Proc Natl Acad Sci USA 2005, 102:18326-18331.

30. Arca B, Lombardo F, Valenzuela JG, Francischetti IMB, Marinotti $O$, Coluzzi M, Ribeiro JAC: An updated catalogue of salivary gland transcripts in the adult female mosquito, Anopheles gambiae. J Exp Biol 2005, 208:397|-3986.

31. Sullivan KF: Structure and utilization of tubulin isotypes. Annu Rev Cell Biol 1988, 4:687-716.

32. Chee HY, AbuBakar S: Identification of a 48 kDa tubulin or tubulin-like C6/36 mosquito cells protein that binds dengue virus 2 using mass spectrometry. Biochem Biophys Res Commun 2004, 320: II-17.

33. Cornet B, Bonmatin JM, Hetru C, Hoffmann JA, Ptak M, Vovelle F: Refined three-dimensional solution structure of insect defensin A. Structure 1995, 3:435-448.

34. Hughes AL: Evolutionary diversification of the mammalian defensins. Cell Mol Life Sci 1999, 56:94-103.

35. Boman HG: Antibacterial peptides: basic facts and emerging concepts. J of Intern Med 2003, 254:197-215.

36. Mygind PH, Fischer RL, Schnorr KM, Hansen MT, Sonksen CP, Lud vigsen S, Raventos D, Buskov S, Christensen B, De Maria L, et al.: Plectasin is a peptide antibiotic with therapeutic potential from a saprophytic fungus. Nature 2005, 437:975-980.

37. Benincasa M, Scocchi M, Podda E, Skerlavaj B, Dolzani L, Gennaro R: Antimicrobial activity of Bac7 fragments against drug-resistant clinical isolates. Peptides 2004, 25:2055-206I. 
38. Frank RW, Gennaro R, Schneider K, Przybylski M, Romeo D: Amino acid sequences of two proline-rich bactenecins. Antimicrobial peptides of bovine neutrophils. J Biol Chem 1990 , 265: $|887|-\mid 8874$.

39. Cabiaux V, Agerberth B, Johansson J, Homble F, Goormaghtigh E, Ruysschaert IM: Secondary structure and membrane interaction of PR-39, a Pro+Arg-rich antibacterial peptide. Eur J Biochem 1994, 224:1019-1027.

40. Bulet P, Stocklin R: Insect antimicrobial peptides: Structures, properties and gene regulation. Protein Pept Lett 2005, I 2:3-I I.

41. Skerlavaj B, Romeo D, Gennaro R: Rapid membrane permeabilization and inhibition of vital functions of gram-negative bacteria by bactenecins. Infect Immun 1990, 58:3724-3730.

42. Kawabata S, Nagayama R, Hirata M, Shigenaga T, Agarwala KL, Saito T, Cho JK, Nakajima H, Takagi T, Iwanaga S: Tachycitin, a small granular component in horseshoe crab hemocytes, is an antimicrobial protein with chitin-binding activity. I Biochem 1996, I 20: I253-I260.

43. Valenzuela JG, Francischetti IMB, Pham VM, Garfield MK, Ribeiro JMC: Exploring the salivary gland transcriptome and proteome of the Anopheles stephensi mosquito. Insect Biochem Mol Biol 2003, 33:717-732.

44. Skerlavaj B, Gennaro R, Bagella L, Merluzzi L, Risso A, Zanetti M: Biological characterization of two novel cathelicidin-derived peptides and identification of structural requirements for their antimicrobial and cell lytic activities. J Biol Chem 1996, 27 I:28375-2838।

45. Lee SY, Moon HJ, Kurata S, Natori S, Lee BL: Purification and cDNA cloning of an antifungal protein from the hemolymph of Holotrichia diomphalia larvae. Biol Pharm Bull I995, I 8: 1049-1052.

46. Lorenzini DM, da Silva PI, Fogaca AC, Bulet P, Daffre S: Acanthoscurrin: a novel glycine-rich antimicrobial peptide constitutively expressed in the hemocytes of the spider Acanthoscurria gomesiana. Dev Comp Immunol 2003, 27:781-79I.

47. Herbiniere J, Braquart-Varnier C, Greve P, Strub JM, Frere J, Van Dorsselaer A, Martin G: Armadillidin: a novel glycine-richantibacterial peptide directed against gram-positive bacteria in the woodlouse Armadillidium vulgare (Terrestrial Isopod, Crustacean). Dev Comp Immunol 2005, 29:489-499.

48. Couillault C, Pujol N, Reboul J, Sabatier L, Guichou JF, Kohara Y, Ewbank J]: TLR-independent control of innate immunity in Caenorhabditis elegans by the TIR domain adaptor protein TIR-I, an ortholog of human SARM. Nature Immunol 2004, 5:488-494.

49. Gandhe AS, Arunkumar KP, John SH, Nagaraju J: Analysis ofbacteria-challenged wild silkmoth, Antheraea mylitta (lepidoptera) transcriptome reveals potential immune genes. BMC Genomics 2006, 7:184.

50. Miura K, Ueno S, Kamiya K, Kobayashi J, Matsuoka H, Ando K, Chinzei $Y$ : Cloning of mRNA sequences for two antibacterial peptides in a hemipteran insect, Riptortus clavatus. Zool Sci 1996, I3:111-117.

51. Altincicek B, Linder M, Linder D, Preissner KT, Vilcinskas A: Microbial metalloproteinases mediate sensing of invading pathogens and activate innate immune responses in the lepidopteran model host Galleria mellonella. Infect Immun 2007, 75:175-183.

52. Crovella S, Antcheva N, Zelezetsky I, Boniotto M, Pacor S, Falzacappa MVV, Tossi A: Primate beta-defensins - Structure, function and evolution. Current Protein \& Peptide Science 2005, 6:7-2I.

53. Langen G, Imani J, Altincicek B, Kieseritzky G, Kogel KH, Vilcinskas A: Transgenic expression of gallerimycin, a novel antifunga insect defensin from the greater wax moth Galleria mellonella, confers resistance to pathogenic fungi in tobacco. Biol Chem 2006, 387:549-557.

54. Rotheray G: Colour guide to hoverfly larvae. Dipterist Digest No. 9 Derek Whiteley, Sheffield, England; 1993.

55. Ausubel FM, Brent R, Kingston RE, Moore DD, Seidman JG, Smith JA Struhl K: Current Protocols in Molecular Biology John Wiley and Sons, New York; 1987.

56. Boman HG, Nilsson-Faye I, Paul K, Rasmusen T]: Insect immunity I. Characteristics of an inducible cell-free antibacterial reactionin hemolymph of Samia cynthia. Infect Immun 1974 I 0: | 36- | 45 .
57. Corpet F: Multiple sequence alignment with hierarchical clustering. Nucleic Acids Res 1988, 16:1088I-10890.

58. Ronquist F, Huelsenbeck JP: MrBayes 3: Bayesian phylogenetic inference under mixed models. Bioinformatics 2003 , 19:1572-1574.

59. Whelan S, Goldman N: A general empirical model of protein evolution derived from multiple protein families using a maximum-likelihood approach. Mol Biol Evol 2001, I 8:69l-699.

60. Henikoff S, Henikoff JG: Amino acid substitution matrices from protein blocks. Proc Natl Acad Sci USA 1992, 89:10915-10919.

61. Page RDM: TREEVIEW: An application to display phylogenetic trees on personal computers. Computer Applications in the Biosciences 1996, I 2:357-358.

62. Huelsenbeck J, Rannala B: Frequentist properties of Bayesian posterior probabilities of phylogenetic trees under simple and complex substitution models. Syst Biol 2004, 53:904-913.

63. Rozen S, Skaletsky H: Bioinformatics Methods and Protocols: Methods in Molecular Biology. In Primer3 on the WWW for general users and for biologist programmers Humana Press, Totowa, NJ; 2000
Publish with Bio Med Central and every scientist can read your work free of charge

"BioMed Central will be the most significant development for disseminating the results of biomedical research in our lifetime. "

Sir Paul Nurse, Cancer Research UK

Your research papers will be:

- available free of charge to the entire biomedical community

- peer reviewed and published immediately upon acceptance

- cited in PubMed and archived on PubMed Central

- yours - you keep the copyright
BioMedcentral 